\title{
The Economics of IPR Protection Policies
}

\author{
RICARD GIL * \\ Department of Economics, UC Santa Cruz
}

\begin{abstract}
In this paper, I model competition between legal and pirate products. In this framework, the government affects competition through police spending and taxes on the legal products. Therefore, the government can choose the optimal combination of spending and taxes that fit better its goals. I show that governments focusing on eradicating piracy will use lower level of taxes and police spending than governments focused on maximizing consumption, consumer surplus, and welfare or government size. This result highlights the importance of demand side policies in the fight against piracy and challenges the traditional solo approach of supply side policies.
\end{abstract}

\section{Introduction}

The growing importance of piracy has become a major concern for governments around the world and media industries managers. The continuous violation of international Intellectual Property Rights (IPR hereafter) laws in developing countries scares away investment from multinational firms resulting in lower growth and consumption paths. Similarly, domestic piracy lowers the return on investment of firms in the media industry driving firms out of business, and eventually lowering industry revenues.

Even though piracy in the movie industry has existed for many years (through homemade copies of video tapes), this has increased lately with the appearance of DVDs and the internet (pirate DVDs and internet downloads). Similarly, the music industry has also suffered the effect of piracy: according to the International Federation of the Photographic Industry (IFPI) global sales increased in the 90's from US\$24.1 billion to US\$38.6 billion. Nevertheless, global sales fell 5\% in 2000, 8.8\% in 2001 and $7.1 \%$ in 2002, reaching a low of US\$30.9 billion (Zentner, 2006).

Although internet piracy (due to the Napster case) has received most attention in this matter, there exist other types of piracy that are as important (may be even more) as internet piracy. An example would be illegal street sales (IFPI 2001, 2002). This is an important worldwide problem (it is easy to find any CD in the streets of Bangkok than it is to find it in a music store in the same city). For example, SGAE (Spanish entity that looks

\footnotetext{
* Mailing address: University of California, Santa Cruz Economics Department, 401 E2 Building, University of California, Santa Cruz, CA 95064. Office Phone number: (831) 459-4924. Email: rgil@ucsc.edu I thank Oriol Garcés, Jordi Gual, Julian Wright and two anonymous referees for their comments and guidance.

Financial aid was received from the SPSP Center at IESE while working on this paper. All errors are mine.
} 
after the interests of authors) reports that Spanish music sales went down by 17 million CDs due to illegal street sales. This means that artists in Spain collected 10 million Euros less than they should have, and record companies collected 150 million Euros less. Even though the importance of this effect has decreased recently, the effect is still large, and it has raised many concerns among artists and media entertainment companies.

In response to these concerns, governments around the world have established different policies to protect the IPR of artists, and therefore preserve the incentives to intellectual creation and technological innovation. These policies have mainly focused in the prosecution of those individuals benefiting from piracy and the conscience-raising of potential buyers of the effects of piracy on the ultimate producers of entertainment, the artists. Only very recently, there has been a proposal to decrease the sale tax on these products as a way to roughen competition for pirate copies. Still, we know very little about the effects of each of these policies, or a combination of them, in lowering the level of music piracy. This paper aims at shedding light into what is the optimal policy to protect IPR.

To study this problem, I use an extension of the model of Shaked and Sutton (1982). In this extension, I limit the number of products to three: a legal product, a pirate product and a composite good. The two former compete directly with each other and have different qualities (legal products have higher quality) and different production technologies. I assume legal producers have a fixed cost of production and linear marginal cost, whereas pirate producers only face a linear marginal cost of production which is presumably lower than the marginal cost of legal producers. These two products also differ in their respective competitive environment. Legal producers are monopolist, while producers of pirate products face perfect competition. The composite good is produced and marketed competitively.

In addition to modeling the private sector, I model the public sector and its interaction with the private producers (both legal and pirate producers). The government can affect the market outcomes through two distinct channels: sale tax and spending. The sales tax only affects legal products, while government spending affects the probability of confiscating the pirate products and therefore reduces expected piracy profitability. The government must then balance the use of both channels to achieve its desired goals. In this paper, I examine five different types of goals that a government may follow when facing piracy as modeled: maximizing total consumption regardless of the product consumed, maximizing consumer surplus, maximizing total welfare, maximizing government size and minimizing piracy.

I find, not surprisingly, that different goals lead to different types of policy with respect to sale taxes and government spending. Governments that aim to maximize its size impose taxes that maximize tax revenues from all goods and therefore spend the most money. Governments that aim to maximize consumer surplus or society welfare impose higher taxes on the goods affected by piracy and spend more on monitoring than they do when they aim to maximize consumption. These three types of government impose lower taxes on the composite good than governments maximizing their size. Finally, governments that aim only to eliminate piracy regardless of everything else impose the lowest taxes on the goods affected by piracy, have the lowest levels of spending and set the highest taxes on the composite good.

These results suggest that if governments are mainly worried about the long term effects of piracy on current innovation, and therefore want to minimize the incidence of 
piracy today, they should rely more on demand side policies rather than otherwise is the case. To do this, they will reduce taxes on the goods affected by piracy and use tax revenues from other goods in the economy to finance spending on prosecuting piracy. This finding is at odds with the traditional view that the government should never use taxes as a tool to fight piracy. Results here also suggest that governments must balance both channels to achieve their goals. Balancing both channels is important because governments face a trade-off between the two: when the government decides to fight piracy by increasing police spending, it may increase taxes to finance the extra spending, but this tax increase just makes pirate products more attractive to consumers since legal products are now more expensive. Governments will use taxation on other goods in the economy to relax this trade-off, although the extent they can do so depends on how elastic the demand of the composite good is relative to the demand of the good subject to piracy.

This paper contributes to an existing literature that treats the economics of IPR policies (Klein, Lerner and Murphy, 2002; and Varian, 2005). The distinct characteristic of this paper is that government decisions are modeled explicitly and included within the competitive interaction that exists between legal and pirate products. Also, I obtain a number of new policy implications and recommendations.

The paper is organized as follows. In the following section, I present the literature review. In section 3, I introduce the theoretical model used in the paper. Section 4 unravels the theoretical implications of the model. In section 5, I compare outcomes across different types of goals that a government may target. Finally, section 6 concludes and provides policy implications.

\section{$2 \quad$ Literature review}

This paper contributes to two recent streams of the literature. They differ in that while one treats this problem from a theoretical point of view, the other examines this issue from an empirical perspective and focus on different aspects of the piracy problem.

Most of the papers in this part of the literature take as a reference seminal papers on the product differentiation, such as Shaked and Sutton (1982), and Wauthy (1996). This paper is not different and takes Shaked and Sutton (1982) as its main reference. Other papers that use this framework to analyze the market for legal and pirate products are Blackburn (2002) and Grgeta (2004). In his paper, Grgeta models the interaction between original and copied products in a dynamic, horizontally and vertically differentiated market. Blackburn introduces network externalities in the study of original and copied goods. He finds not surprisingly that monopolist should only allow casual copying in the presence of large network externality effects. This paper differs from Blackburn (2002) and Grgeta (2004) in that I focus on the government intervention in these markets and not the private sector decisions. Very recently, Varian (2005) surveys the literature and describes some of the insights from previous work. He proposes that a combination of free content policy and traditional copyright policy should do an adequate job to satisfy the society's demand for information goods.

Most of these papers are a direct consequence of the current intellectual debate on the extent of protection over intellectual property rights. Lessig (2004) is a clear example of the existing debate on what is the optimal degree of intellectual protection and the side benefits of the "free dissemination of culture". Other examples of this debate are Besen 
and Raskind (1991), Dam (1999), Klein, Lerner and Murphy (2002), Romer (2002), Slive and Bernhart (1998), and Takeyama (1994, 1997).

On the other hand, I divide the empirical literature in two main groups: those papers analyzing on-line piracy and illegal download through file-sharing, and those papers analyzing all the other types of piracy. The first group of papers received a lot of attention due to the importance of the Napster case. Fine (2000) and Landes and Lichtman (2003) provide direct discussion on the case. The main empirical papers in this area are Blackburn (2005), Oberholzer and Strumpf (2004), Rob and Waldfogel (2004) and Zentner (2006). Blackburn (2005) examines the effect of on-line downloads in music retail sales and finds that on-line downloads work as demand advertisements for small artists, but they work as demand substitutes for big artists. Rob and Waldfogel (2004) collect data on album purchase and download, and find that each download decreases purchase probability by 20 percent. They also find, thanks to valuation data, that downloading decreases expenditure and increase the welfare of those downloading (not the musicians, of course). Zentner (2006) uses a European cross section data set to estimate the effect of music downloads on purchasing probability. He finds that peer-to-peer usage reduces the probability of purchases by $30 \%$. Finally, Oberholzer and Strumpf (2004) find that downloading has no statistical or significant economic impact on music purchases. This evidence goes against all the other papers described before and certainly leaves the door open to new papers that can help answer the bigger question of what is the appropriate level of property rights protection. $^{1}$

The second group provides evidence from other piracy types. Chen and Png (2004), and Hui and Png (2003) are examples of this. Chen and Png (2004) document how legalization of parallel imports reduces CDs prices by 7.2\%. Hui and Png (2003) estimate losses from piracy to be lower than claimed by the industry. They also find that prices would have increased in the absence of piracy. Therefore, losses in revenue are larger than actual losses. From a more general perspective, Hann, Hui, Lee and Png (2002) estimate the value of online information privacy.

As commented above, the paper here is among the first to model explicitly the role of the government in the provision of policies to protect intellectual property rights. To my knowledge, three other papers before have attempted to do this. Banerjee (2003) examines the incentives of a monopolist to prevent commercial piracy and introduces network effects into the analysis. Gayer and Shy (2003) analyzes the consequences of taxes on welfare in the interaction between software and hardware producers. Finally, Chen and Png (2003) have the most similar approach to mine. They model the use of penalties and taxes as the main policy tools to stop piracy. The approach here differs from theirs in that I introduce vertical differentiation and the supply side into the analysis. Examining the trade-offs that the government must take into account when designing policies and depicting how different policies manifest in tax levels and government spending are the goals of my paper.

\footnotetext{
${ }^{1}$ Other papers treating the Napster case and related issues are Fine (2000) and Liebowitz (2003a, 2003b, 2004).
} 


\section{Theoretical model}

I model an economy where consumers consume two goods. I assume that the first of the goods is subject to illegal production and consumers consume either one or zero units of it. Their choice is on whether to consume the legal product or the illegal product. The second good is a composite good $\mathrm{z}$ that is not subject to illegal production and has a downward sloping demand function $Z\left(p_{z}\right)$, where $Z^{\prime}<0$. Following the model developed in Tirole $(1991),{ }^{2}$ I model the choice of legal versus illegal products and assume that individuals have a utility of consumption of the first good such that

$$
U=\theta s-p,
$$

where $\theta$ is the quality of the product consumed by the individual, $s$ is the individual's taste for quality and $p$ is the price paid for the product. Legal and illegal products have different quality levels $\theta_{2}$ (legal) and $\theta_{1}$ (illegal) respectively, where $\theta_{2}>\theta_{1} \cdot{ }^{3}$ Given this notation, the legal product will have a price of $p_{2}$ and the illegal product will have a price $p_{1}$. I also assume that the population's taste for quality is uniformly distributed such that $s \sim U[0, k]$. Finally, for simplicity I assume the population size is $k$.

Given this characterization, any given individual $\mathrm{s}$ will choose to consume the legal product over the illegal product if

$$
\theta_{2} s-p_{2}>\theta_{1} s-p_{1}
$$

so that all consumer with taste higher than $s^{*}=\frac{p_{2}-p_{1}}{\theta_{2}-\theta_{1}}$ will consume the legal product, and all those with taste lower than $s^{*}$ will choose to consume the illegal product or not to consume at all. If I assume that individuals not consuming obtain zero utility, only those consumers with taste higher than $s^{\prime}=\frac{p_{1}}{\theta_{1}}$ would choose the illegal product over nothing (see Figure 1). Therefore, legal and illegal products face the following demand functions that I call hereafter expression (1) and expression (2)

$$
D_{2}=\left[k+\frac{p_{1}}{\Delta \theta}\right]-\frac{p_{2}}{\Delta \theta}
$$

and

$$
D_{1}=\frac{p_{2}}{\Delta \theta}-\left[\frac{\theta_{2}}{\theta_{1} \Delta \theta}\right] p_{1}
$$

where $\Delta \theta=\theta_{2}-\theta_{1}$.

This implies, $D_{1}>0$ if $s^{*}>s^{\prime}$, that is, if $\frac{p_{2}-p_{1}}{\theta_{2}-\theta_{1}}>\frac{p_{1}}{\theta_{1}}$, or $\frac{p_{2}}{p_{1}}>\frac{\theta_{2}}{\theta_{1}}$. These are all well-known results in the product differentiation literature and constitute the characterization of the demand side in this paper.

\footnotetext{
${ }^{2}$ The model in Tirole (1991) is a version of the model in Shaked and Sutton (1982).

${ }^{3}$ This difference in "quality" can capture the morals of people, differences in reliability or just differences in simple quality.
} 


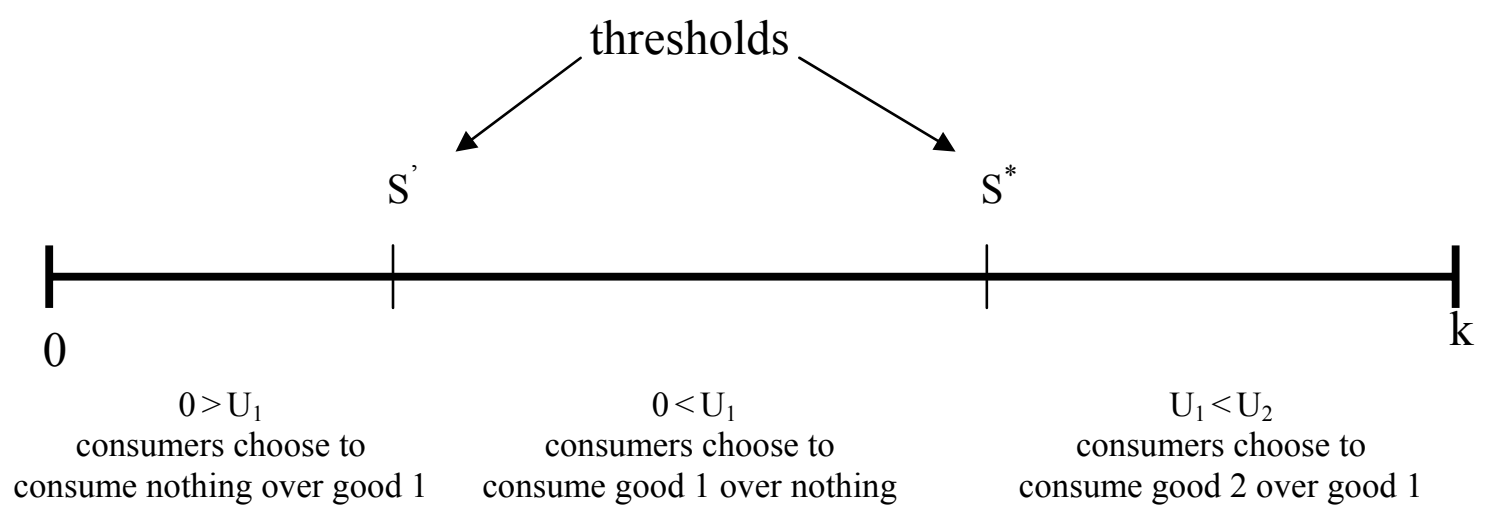

Figure 1

\subsection{Public sector}

In this economy, I assume there is a public sector or government. The government spends a fixed amount $R$ in services provided to consumers. The government can also spend a variable amount $G$ on prosecuting crime (producers of illegal products). The more the government spends, the higher the probability the government will capture the producers of illegal products. This probability depends on $G$ through the function $h(G)$, where $h(0)=0, h(\infty)=1$ and $h^{\prime}>0, h^{\prime \prime} \leq 0$.

The government collects quantity taxes $t_{2}$ and $t_{z}$ from both taxable goods in this economy to finance all its spending $G+R$. Therefore, when the government decides what tax to collect and how much to spend in fighting crime, it has to obey a budget constraint such that

$$
q_{2} t_{2}+Z t_{Z}=G+R
$$

where $q_{2}$ is the quantity of units sold of the legal product, $Z$ is the quantity of units sold of the composite good $z$, and $t_{2}$ and $t_{z}$ are the quantity taxes on both goods respectively.

Notice that the government cannot collect tax revenue from the sale of illegal products since the definition of an illegal product entails that its price escapes any government control including taxes. Therefore the government can increase $q_{2}$ and its tax revenues by increasing its spending $G$, holding $t_{z}$ constant. Despite this, there is a trade-off between $G$ and $t_{2}$ that the government must be aware of: increases in $G$ must be financed through increases in tax collection. When this increase in tax collection comes from increasing tax $t_{2}$, the demand for illegal products increases, perhaps more than the opposite effect of 
increasing spending $G$ in the first place. ${ }^{4}$ This trade-off is attenuated by the existence of $\operatorname{tax} t_{z}$ on the composite good $z$ since the government could use the tax revenues obtained from $\operatorname{good} z$ to finance part of the spending $G$.

\subsection{Private sector}

There are three products in this economy, two legal products $\left(q_{2}\right.$ and $\left.z\right)$ and one illegal $\left(q_{1}\right)$. Since the aim of the paper is to depict ultimately a simplified version of reality, I characterize the legal product $q_{2}$ as one where a monopolist takes care of all the production. This is a plausible assumption since legal producers create a new product for which they have monopolistic power. On the other hand, I assume that there is perfect competition in both the market for the composite good $z$ and the illegal product $q_{1}$ and therefore there is firm entry until profits are driven down to zero. Once the invention is introduced by the legal monopolist, illegal producers instantly get access to a copying technology that allows them to produce an imperfect copy of the legal product. This copying technology is accessible to everybody and for this reason the market for imperfect copies (illegal products) is perfectly competitive.

The profit function of the legal firm is

$$
\Pi_{2}=D_{2}\left(p_{2}\right) p-C_{2}\left(D_{2}\left(p_{2}\right)\right)
$$

where $p_{2}=p+t$ and $C_{2}($.$) is the cost function of the legal producer. Note that the legal$ producer optimally sets $p$, but $t$ is given exogenously to the legal producer by the government. Similarly, the profit function for any of the firms in the illegal sector will be

$$
\Pi_{1}=d_{1}\left(p_{1}\right) p_{1}[1-h(G)]-C_{1}\left(d_{1}\left(p_{1}\right)\right)
$$

Here $d_{1}\left(p_{1}\right)$ is the demand for each firm in the illegal sector, $C_{1}($.$) is the cost function of$ each firm, and $h(G)$ is the probability of getting caught by the government. If caught, the illegal producer must still pay the cost of production (the goods are produced ex-ante) and must give away all revenues from the sale. ${ }^{5}$

Even though I describe profit functions above, technology and cost structure need further discussion. For simplicity, I assume the cost function of the legal firm will be such that

$$
C_{2}=c_{2} q_{2}+F
$$

and that of the illegal firms will be such that

$$
C_{1}=c_{1} q_{1}
$$

where $q_{2}$ and $q_{1}$ are quantities produced by legal and illegal firms respectively, $F$ is the fixed cost incurred by the legal firm to create the innovation, and $c_{2}$ and $c_{1}$ are marginal

\footnotetext{
${ }^{4}$ This paper does not deal with regulation and assumes the punishment for being caught is profit confiscation. An increase in $G$ could be as well viewed as an increase in the punishment if caught since it lowers the expected profits of illegal producers.

${ }^{5}$ Another possibility is to add a fine if captured by police. Results do not change from the analysis here when the government sets a fine per unit of illegal product confiscated. It does not hold if fine size is independent of the number of units of illegal product. Despite this, a big enough credible fine could deter illegal producers from going into business. To be effective, the probability of apprehension should be still positive $(G>0)$ and the expected fine (probability $\mathrm{x}$ fine) equal or bigger than potential profits.
} 
costs where $c_{2}>c_{1}$ due to the lower quality of the illegal product. ${ }^{6}$ I assume the composite $\operatorname{good} \mathrm{z}$ is produced at some constant marginal cost.

Following the theoretical framework in this section, I examine the interaction of private and public sector agents in the following section. I first examine pricing decisions by firms, and then I look into the different policies that the government can follow. The optimal policy will depend on the ultimate goal of the government.

\section{$4 \quad$ Theoretical implications}

This section develops the theoretical framework presented in the previous section. I first start analyzing the decisions of the private sector, and then I proceed to analyze the decisions of the public sector.

\subsection{Private sector decisions}

As described above, the illegal sector is perfectly competitive. This means that profit will be driven to zero, and therefore expression (5) becomes

$$
\Pi_{1}=d_{1}\left(p_{1}\right) p_{1}[1-h(G)]-C_{1}\left(d_{1}\left(p_{1}\right)\right)=0 .
$$

This equation transforms into

$$
\Pi_{1}=d_{1}\left(p_{1}\right)\left(p_{1}[1-h(G)]-c_{1}\right)=0
$$

when includes the cost function described above. I then find the price for the illegal product such that

$$
p_{1}=\frac{c_{1}}{1-h(G)} .
$$

On the other hand, the monopolistic legal producer takes into account the price set by the illegal producers $p_{1}$ and the tax $t_{2}$ set by the government. From expression (4), I find that the legal producer maximizes profits such that

$$
\max _{p} D_{2}\left(p+t_{2}\right)\left(p-c_{2}\right)-F,
$$

where $D_{2}$ comes from expression (1) above. Out of the first order condition of the legal producer problem, I obtain expression (7) that defines $p$ in terms of $p_{1}$ such that

$$
p=\frac{k \Delta \theta+p_{1}+t_{2}+c_{2}}{2} .
$$

This means that once I include the equilibrium $p_{1}$, the equilibrium price is

$$
p=\frac{k \Delta \theta+\frac{c_{1}}{1-h(G)}+t_{2}+c_{2}}{2} .
$$

This solution establishes that taxes $\left(t_{2}\right)$, costs $\left(c_{1}\right.$ and $\left.c_{2}\right)$, probability of apprehension $(h(G))$, market size $(k)$ and quality differential $(\Delta \theta)$ increase the price charged by the monopolistic legal producer. ${ }^{7}$

\footnotetext{
${ }^{6}$ This assumption could be relaxed and let $c_{2}=c_{1}$ or even $c_{2}<c_{1}$. Under such circumstances $p_{1}$ will be close to $p_{2}$ if not higher. This would drive pirate producers out of business since consumers will not buy lower quality products at higher prices.
} 
So far as the composite good $z$ is concerned, the price paid by consumers will be $p_{z}+t_{z}$, where $p_{z}$ is the constant marginal cost of producing the good. This means that the consumers fully absorb the tax imposed on $z$ and therefore the level of taxation on $z$ will depend on its elasticity of demand and how elastic this is relative to the demand of $q_{2}$.

\subsection{Public sector decisions}

Once the government knows how firms react to its decisions on sales tax $\left(t_{2}\right.$ and $\left.t_{z}\right)$ and police spending $(G)$, it sets optimal taxes and optimal level of spending that helps better to achieve its goals. Therefore defining the different type of goals of a government defines as well what the optimal policy is.

The monopolistic legal firm must always obtain positive profit, since the illegal sector copies come from their invention. This assumption can be relaxed if it is understood that local pirate producers are copying the products from foreign legal producers. This eventually will lead the local legal producers out of business and the illegal producers would prevail.

\subsubsection{Maximizing consumption}

Take for example the case that the government wants to maximize overall consumption, that is, joint consumption of legal, illegal products and the composite good. This is a case where governments value all consumers alike and therefore weigh them the same. In that case, the government maximizes

$$
\max _{t_{2}, t_{z}, G} D_{1}\left(p_{1}\right)+D_{2}\left(p_{2}\right)+Z\left(p_{z}+t_{z}\right)
$$

subject to $p_{2}=p+t$, and expressions (3), (6) and (8).

Once I substitute in the values of $p$ and $p_{1}$, the problem transforms to

$$
\max _{t_{2}, t_{z}, G} k-\frac{c_{1}}{(1-h(G)) \theta_{1}}+Z\left(p_{z}+t_{z}\right)
$$

subject to

$$
\left[\frac{k \Delta \theta+\frac{c_{1}}{1-h(G)}-3 t_{2}-c_{2}}{2 \Delta \theta}\right] t_{2}+Z\left(p_{z}+t_{z}\right) t_{Z}=G+R .
$$

As a result to differentiating this problem I obtain four first order conditions $\left(t_{2}, t_{z}, G\right.$ and $\lambda$ ) such that

$$
\begin{gathered}
-\frac{c_{1} h^{\prime}(G)}{\theta_{1}(1-h(G))^{2}}+\lambda-\lambda \frac{t_{2} c_{1} h^{\prime}(G)}{2 \Delta \theta(1-h(G))^{2}}=0, \\
-k \Delta \theta-\frac{c_{1}}{1-h(G)}+3 t_{2}+c_{2}+3 t_{2}=0, \\
Z^{\prime}+\lambda\left(-Z^{\prime} t_{z}-Z\right)=0
\end{gathered}
$$

\footnotetext{
${ }^{7}$ If we assumed the illegal producer is also a monopolist of the lower quality product, the results do not change much since

$$
p=\frac{2 k \Delta \theta+\frac{c_{1}}{1-h(G)}+\left(2+\frac{\theta_{1}}{\theta_{2}}\right) t_{2}+2 c_{2}}{4+\frac{\theta_{1}}{\theta_{2}}} .
$$
}


and

$$
\left[\frac{k \Delta \theta+\frac{c_{1}}{1-h(G)}-3 t_{2}-c_{2}}{2 \Delta \theta}\right] t_{2}+Z t_{z}=G+R .
$$

Notice that $t_{2}$ does not appear in the objective function and it only appears in the government budget constraint. On the other hand, $G$ affects directly both objective function and budget constraint. This conditions the resulting first order conditions. In particular, the first order condition with respect to $G$ shows how increases in $G$ directly decreases consumption, but it indirectly favors consumption through the budget constraint and the marginal utility of government spending $\lambda$. In the case of the first order condition with respect to $t_{2}$, the maximization problem only maximizes the budget constraint and therefore the optimal tax $t_{2}$ is the tax that maximizes tax revenue for any given $G$. The first order condition with respect to $t_{z}$ shows that the government will choose a tax $t_{z}$ such that the elasticity of demand $Z$ is above 1 . Otherwise, $\lambda$ would take $\infty$ or a negative value.

\subsubsection{Maximizing surplus}

A second possible case arises when governments maximize consumer surplus. This case differs from the first in that the government no longer values all consumers the same. Here the government values more those consumers that have a higher valuation of consumption of good $q_{2}$ and therefore the government will favor them when making decisions on tax and expenditure levels. In that case, the government maximizes

$$
\max _{t_{2}, t_{z}, G} \int_{s^{*}}^{k}\left(\theta_{2} v-p_{2}\right) d v+\int_{\frac{p_{1}}{\theta_{1}}}^{s^{*}}\left(\theta_{1} v-p_{1}\right) d v+\int_{p_{z}+t_{z}}^{\infty} Z(v) d v
$$

subject to $p_{2}=p+t$, and expressions (3), (6) and (8).

Note that there will be a share of consumers that choose not to consume any good. These obtain zero surplus (utility) from consumption and therefore do not enter into the government's objective function.

After plugging values of $p$ and $p_{1}$, the problem transforms into

$$
\max _{t_{2}, t_{z}, G} \theta_{2} k-\frac{c_{1}}{(1-h(G)) \theta_{1}}-\left[\frac{k \Delta \theta-\frac{c_{1}}{1-h(G)}+3 t_{2}+c_{2}}{2}\right]+\int_{p_{z}+t_{Z}}^{\infty} Z(v) d v
$$

subject to

$$
\left[\frac{k \Delta \theta+\frac{c_{1}}{1-h(G)}-3 t_{2}-c_{2}}{2 \Delta \theta}\right] t_{2}+Z\left(p_{z}+t_{z}\right) t_{Z}=G+R .
$$

This problem will yield four first order conditions such as

$$
\begin{gathered}
-\frac{c_{1} h^{\prime}(G)}{\theta_{1}(1-h(G))^{2}}+\frac{c_{1} h^{\prime}(G)}{2(1-h(G))^{2}}-\lambda \frac{t_{2} c_{1} h^{\prime}(G)}{2 \Delta \theta(1-h(G))^{2}}+\lambda=0, \\
-\frac{3}{2}+\lambda\left[\frac{3 t_{2}}{2 \Delta \theta}-\frac{k \Delta \theta+\frac{c_{1}}{1-h(G)}-3 t_{2}-c_{2}}{2 \Delta \theta}\right]=0,
\end{gathered}
$$




$$
\int_{p_{z}+t_{z}}^{\infty} Z^{\prime}(v) d v-Z+\lambda\left(-Z^{\prime} t_{z}-Z\right)=0
$$

and

$$
\left[\frac{k \Delta \theta+\frac{c_{1}}{1-h(G)}-3 t_{2}-c_{2}}{2 \Delta \theta}\right] t_{2}+Z t_{z}=G+R .
$$

In this case, both $t_{2}$ and $G$ affect directly and indirectly the objective function. Notice that when the government maximizes consumer surplus, it is implicitly valuing more those consumers with high value of quality consumption than those with lower value of quality consumption. Because of this, even with the loss of consumers experienced when $G$ increases, holding tax $t_{2}$ constant, there is a benefit increasing spending $G$ because there will be more consumers choosing the legal product over the pirate product. On the other hand, since $t_{2}$ now affects directly both objective function and government budget constraint, the first order condition with respect to $t_{2}$ differs from the one in the consumption-maximizing government case. Since an increase in tax harms those consumers that value consumption the most (consumers of legal products), there is a constant negative effect of an increase in $t_{2}(-3 / 2)$. The first order condition with respect to $t_{z}$ shows that the optimal choice of $t_{z}$ will balance the loss in consumer surplus and the gain in tax revenues from good $z$ due to a marginal increase in $t_{z}$. This implies that in situations where the loss in consumer surplus is small, the government may use tax revenues from good $z$ to subsidize consumption of good $q_{2}$ and lower $t_{2}$ holding spending $G$ constant.

\subsubsection{Maximizing welfare}

The objective function does not differ much from the surplus-maximizing case when the government wants to maximize welfare. The objective function will now include the profits of the legal and illegal producers. Therefore, the new objective function will be

$$
\max _{t_{2}, t_{z}, G} \int_{s^{*}}^{k}\left(\theta_{2} v-p_{2}\right) d v+\int_{\frac{p_{1}}{\theta_{1}}}^{s^{*}}\left(\theta_{1} v-p_{1}\right) d v+\int_{p_{z}+t_{z}}^{\infty} Z(v) d v+\Pi_{2}\left(p_{2}, p_{1}\right)
$$

subject to $p_{2}=p+t$, and expressions (3), (4), (6) and (8).

Note that $\Pi_{1}\left(p_{2}, p_{1}\right)=0$ since the market for illegal products is assumed to be perfectly competitive. Then after plugging values for the prices $p$ and $p_{1}$, I obtain

$$
\begin{gathered}
\max _{t_{2}, t_{z}, G} \theta_{2} k-\frac{c_{1}}{(1-h(G)) \theta_{1}}-\left[\frac{k \Delta \theta-\frac{c_{1}}{1-h(G)}+3 t_{2}+c_{2}}{2}\right]+\int_{p_{z}+t_{Z}}^{\infty} Z(v) d v+ \\
k \Delta \theta+\frac{c_{1}}{1-h(G)}-3 t_{2}-c_{2}-k \Delta \theta+\frac{c_{1}}{1-h(G)}+t_{2}-c_{2} \\
+\left[\frac{k \Delta \theta}{2}\right]-F
\end{gathered}
$$

subject to 


$$
\left[\frac{k \Delta \theta+\frac{c_{1}}{1-h(G)}-3 t_{2}-c_{2}}{2 \Delta \theta}\right] t_{2}+Z\left(p_{z}+t_{z}\right) t_{Z}=G+R .
$$

This problem yields the following first order conditions (after simplifying a bit),

$$
\begin{gathered}
-\frac{1}{\theta_{1}}+\frac{1}{2}+\left[\frac{k \Delta \theta+\frac{c_{1}}{1-h(G)}+t_{2}-c_{2}}{4 \Delta \theta}\right]+\left[\frac{k \Delta \theta+\frac{c_{1}}{1-h(G)}-3 t_{2}-c_{2}}{4 \Delta \theta}\right]-\lambda \frac{t_{2}}{2 \Delta \theta}+\lambda \frac{(1-h(G))^{2}}{c_{1} h^{\prime}(G)}=0, \\
-\frac{3}{2}+3\left[\frac{k \Delta \theta+\frac{c_{1}}{1-h(G)}+t_{2}-c_{2}}{4 \Delta \theta}\right]+\left[\frac{k \Delta \theta+\frac{c_{1}}{1-h(G)}-3 t_{2}-c_{2}}{4 \Delta \theta}\right]+\lambda\left[\frac{3 t_{2}}{2 \Delta \theta}-\frac{k \Delta \theta+\frac{c_{1}}{1-h(G)}-3 t_{2}-c_{2}}{2 \Delta \theta}\right]=0, \\
\int_{p_{z}+t_{z}}^{\infty} Z^{\prime}(v) d v-Z\left(p_{z}+t_{z}\right)+\lambda\left(-Z^{\prime} t_{z}-Z\right)=0
\end{gathered}
$$

and

$$
\left[\frac{k \Delta \theta+\frac{c_{1}}{1-h(G)}-3 t_{2}-c_{2}}{2 \Delta \theta}\right] t_{2}+Z\left(p_{z}+t_{z}\right) t_{Z}=G+R .
$$

Similarly to the previous case, $t_{2}$ and $G$ affect here directly and indirectly the welfare objective function. In this case, an increase in $G$ not only favors consumption of the legal product (and therefore increases consumer surplus) but also decreases the competition that the legal producer faces. This increases the legal producer profits and therefore society welfare. On the other hand, increases in $t_{2}$ would reduce society welfare through decreases in the legal producer profits and a reduction of demand of legal product consumption by those consumers with high valuation of consumption. The first order condition with respect to $t_{z}$ is the same as that when the government aims to maximize surplus. Therefore, in this case the gains of subsidizing consumption of good $q_{2}$ by taxing heavily good $z$ are even stronger than in the case when governments aim to maximize surplus. ${ }^{8}$

\subsubsection{Maximizing government size}

A fourth case could be one where the politician in charge of making decisions cares about the size of the government because that reflects her power in society. Here the government no longer cares about the surplus or consumption of individuals, but only about its size. In such a case, the government will maximize government spending such that

$$
\max _{t_{2}, t_{z}, G} G+R
$$

subject to $p_{2}=p+t$, and expressions (3), (6) and (8).

Note that in a case like this, the bureaucrat would be involuntarily eliminating piracy since it is in her interest to increase the demand for the legal product and diminish the demand for the illegal product.

After plugging in values for $p$ and $p_{1}$, the resulting problem is

\footnotetext{
${ }^{8}$ An extension of this case would be that when the government aims to maximize "legal" welfare, that is, surplus from consumption of the legal good and profits of the legal producer only. In this case, the government does not place any value on consumption of those consumers with low s and would want to lower taxes on the legal product and maximize spending $G$ with tax revenues collected through $Z$.
} 
subject to

$$
\max _{t_{2}, t_{z}, G} G+R
$$

$$
\left[\frac{k \Delta \theta+\frac{c_{1}}{1-h(G)}-3 t_{2}-c_{2}}{2 \Delta \theta}\right] t_{2}+Z\left(p_{z}+t_{z}\right) t_{Z}=G+R .
$$

Hence I obtain the following first order conditions

$$
\begin{gathered}
1+\lambda-\lambda \frac{c_{1} h^{\prime}(G) t_{2}}{2 \Delta \theta(1-h(G))^{2}}=0, \\
-\frac{3 t_{2}}{2 \Delta \theta}+\left[\frac{k \Delta \theta+\frac{c_{1}}{1-h(G)}-3 t_{2}-c_{2}}{2 \Delta \theta}\right]=0, \\
Z^{\prime} t_{z}+Z=0
\end{gathered}
$$

and

$$
\left[\frac{k \Delta \theta+\frac{c_{1}}{1-h(G)}-3 t_{2}-c_{2}}{2 \Delta \theta}\right] t_{2}+Z\left(p_{z}+t_{z}\right) t_{Z}=G+R .
$$

The first orders conditions with respect to $t_{2}$ and $t_{z}$ show that this government will tax goods $q_{2}$ and $z$ up to the point where their elasticities of demand are equal to 1 and therefore tax revenues are maximized.

\subsubsection{Minimizing piracy}

Finally, the government could have an active direct policy to eliminate piracy as much as possible. In this case, the only objective of the government would be to minimize the demand for the illegal product. This case is analogous to a situation where the government cares about the future incentives to innovation, and therefore decides to eradicate current piracy at all cost. Again, here the government will pursue its goal regardless of the consequences on consumer welfare or the profits of legal producers. Therefore, the minimizing problem of the government would become

$$
\min _{t_{2}, t_{z}, G} D_{1}\left(p_{1}\right)
$$

subject to $p_{2}=p+t$, and expressions (3), (6) and (8).

This problem transforms into

$$
\min _{t_{2}, t_{z}, G} \frac{k \Delta \theta-\frac{c_{1}}{1-h(G)}+3 t_{2}+c_{2}}{2 \Delta \theta}-\frac{c_{1}}{\theta_{1}(1-h(G)}
$$

subject to

$$
\left[\frac{k \Delta \theta+\frac{c_{1}}{1-h(G)}-3 t_{2}-c_{2}}{2 \Delta \theta}\right] t_{2}+Z\left(p_{z}+t_{z}\right) t_{Z}=G+R .
$$

After differentiating, I obtain the following first order conditions

$$
-\frac{c_{1} h^{\prime}(G)}{2 \Delta \theta(1-h(G))^{2}}-\frac{c_{1} h^{\prime}(G)}{\theta_{1}(1-h(G))^{2}}+\lambda-\lambda \frac{t_{2} c_{1} h^{\prime}(G)}{2 \Delta \theta(1-h(G))^{2}}=0,
$$




$$
\frac{3}{2 \Delta \theta}+\lambda\left(\frac{3 t_{2}}{2 \Delta \theta}-\frac{k \Delta \theta+\frac{c_{1}}{1-h(G)}-3 t_{2}-c_{2}}{2 \Delta \theta}\right)=0,
$$

and

$$
\left[\frac{k \Delta \theta+\frac{c_{1}}{1-h(G)}-3 t_{2}-c_{2}}{2 \Delta \theta}\right] t_{2}+Z\left(p_{z}+t_{z}\right) t_{Z}=G+R .
$$

Note from the first order condition with respect to $G$ that increases in $G$ will reduce demand of the pirate product at decreasing rates. Therefore, governments minimizing piracy will choose their optimal levels of taxes and spending such that the marginal unit of spending $G$ decreases piracy by the same amount that the last unit of tax revenue collected increases piracy. Notice from the first order condition with respect to $t_{2}$ that a decrease in $t_{2}$ decreases piracy (positive factor $\frac{3}{2 \Delta \theta}$ ), and therefore the optimal tax $t_{2}$ will be below the tax level that maximizes tax revenues since the government will choose $t_{2}$ such that the elasticity of demand is above 1 . On the contrary, the government chooses $t_{z}$ so that it maximizes the tax revenue from good $z$. This means in this case taxes from good $z$ will finance part of the spending $G$ used to monitor piracy.

\section{$5 \quad$ Comparing policies}

To evaluate and compare the different government policies presented above, I give a definite functional form to $h(G)$. I choose the following function

$$
h(G)=\frac{G}{1+G} .
$$

This function fulfills all the initial assumptions about $h(G)$, that is, $h(0)=0, h(\infty)=1$, $h^{\prime}>0$ and $h^{\prime \prime}<0$.

Using this function for the probability function $h(G)$ simplifies the first order conditions above with respect to the government spending $G$. Despite this simplification and because of the quadratic form of the government budget constraint, there is no close solution to $G, t_{2}$ and $t_{z}$ for each one of the government examples set above. ${ }^{9}$ Still I can analyze the different policies and compare them against each other using objective functions and first order conditions above.

\footnotetext{
${ }^{9}$ When substituting into the first order conditions our function for $h(G)$, $G$ disappears from the first order conditions. $G$ does not disappear from the first order conditions with respect to $t_{2}$. This leaves us with one equation that solves $\lambda$ in terms of $t_{2}$ and other parameters of the model, one equation that sets $t$ in terms of $G$ and possibly $\lambda$, and the budget constraint. The lack of closed solutions comes from the quadratic form of the government budget constraint.
} 


\subsection{Government spending}

The objective function of the government that maximizes consumption depends negatively on the level of spending $G\left(-\frac{c_{1}}{\theta_{1}(1-h(G))}\right)$. That differs from the objective function of the government maximizing surplus in that this negative relationship is softened by an extra term that depends positively on the level of spending $G\left(-\frac{c_{1}}{\theta_{1}(1-h(G))}+\frac{c_{1}}{2(1-h(G))}\right)$. In this second case, the whole objective function would depend positively of $G$ for all values of $\theta_{1}>2$. As there is no clear solution to the systems of equations presented in the previous section, I can only compare how the different objective functions depend on the level of spending $G$. When comparing governments that maximize consumption and governments that maximize surplus, the former's objective function is more strongly negative related to spending $G$ than the latter's objective function. This implies that $G^{S}>G^{c}$.

When examining the government that maximizes welfare, its objective function is the same as that of the government maximizing surplus with the addition of the profit of the legal producer. These profits increase with the level of spending $G$ since government spending increases the price of pirate products, harms pirate profits and increases the profits of the legal producer. Therefore, this objective function has a stronger positive relationship to $G$ than the objective function of the government maximizing surplus. This circumstance makes it obvious that $G^{w}>G^{s}$.

The case of the government maximizing its size is the clearest of all. Its objective function contains the term $G$ on it which implies that the incremental gains of the objective function are positive and constant for all values of $G$. The fact that the government taxes both goods up to the point where elasticities are equal to one ensure that the level of spending is higher than in any other case and therefore $G^{r}>G^{w}$.

Finally, the objective function of the government minimizing piracy depends negatively on $G$, even more strongly than the objective function of the government maximizing consumption $\left(-\frac{c_{1}}{2 \Delta \theta(1-h(G))}-\frac{c_{1}}{\theta_{1}(1-h(G))}\right)$. Therefore, the level of spending $G$ of such government will be lower than that of the government maximizing consumption.

In conclusion, one inequality summarizes the discussion in this section,

$$
G^{r}>G^{w}>G^{s}>G^{c}>G^{p} \text {. }
$$

\subsection{Consumption tax}

Even though close solutions are not available, I can say much about taxes by looking at the first order conditions of maximizing the respective objective functions with respect to the $\operatorname{tax} t_{2}$. I find the following tax profiles,

$$
t_{2}^{c}=\frac{\frac{c_{1}}{1-h}-c_{2}}{6}+\frac{k \Delta \theta}{6},
$$




$$
\begin{gathered}
t_{2}^{s}=\frac{\frac{c_{1}}{1-h}-c_{2}}{6}+\frac{k \Delta \theta}{6}+\frac{\Delta \theta}{2 \lambda}, \\
t_{2}^{w}=\frac{2(1+\lambda)}{\lambda-1}\left(\frac{\frac{c_{1}}{1-h}-c_{2}}{6}+\frac{k \Delta \theta}{6}\right)+\frac{\Delta \theta-\lambda}{\lambda-1}, \\
t_{2}^{r}=\frac{\frac{c_{1}}{1-h}-c_{2}}{6}+\frac{k \Delta \theta}{6}
\end{gathered}
$$

and

$$
t_{2}^{p}=\frac{\frac{c_{1}}{1-h}-c_{2}}{6}+\frac{k \Delta \theta}{6}-\frac{1}{2 \lambda},
$$

where $t_{2}^{c}$ is the optimal tax profile if the government maximizes consumption, $t_{2}^{s}$ the tax profile if the government maximizes consumer surplus, $t_{2}^{w}$ the tax profile when the government maximizes welfare, $t_{2}^{r}$ the optimal tax profile if the government maximizes tax revenue, and $t_{2}^{p}$ the optimal tax profile when the government minimizes piracy.

From comparing these five different optimal tax profiles, and holding spending $G$ constant, taxes compare to each other such that

and

$$
\begin{aligned}
& t_{2}^{p}<t_{2}^{c}=t_{2}^{r}, \\
& t_{2}^{c}=t_{2}^{r}<t_{2}^{s},
\end{aligned}
$$

$$
t_{2}^{c}=t_{2}^{r}<t_{2}^{w}
$$

The last inequality holds as long as $\lambda>1$. This will always be the case because a value $\lambda \leq 1$ would yield negative tax values and in this paper subsidies are not allowed.

\subsection{Composite good tax}

In this section, I compare the level of taxation on the composite good $z$. Since the demand for $z$ is left as $Z\left(\right.$.), I compare the optimal tax $t_{z}$ across government goals through the values of the elasticity of the demand of $z\left(\varepsilon_{z}=\frac{d Z}{d t_{z}} \frac{t_{z}}{Z}\right)$ that I obtain out of the first order conditions with respect to $t_{z}$.

From the expressions above, governments that are either maximizing size or minimizing piracy will tax good $z$ equally and up to the point where $\left|\varepsilon_{z}^{r}\right|=\left|\varepsilon_{z}^{p}\right|=1$. On the other hand, governments maximizing surplus or welfare will tax equally and up to the point where

$$
\left|\varepsilon_{z}^{s}\right|=\left|\varepsilon_{z}^{w}\right|=1+\frac{1}{\lambda}\left(1-\frac{\int Z^{\prime}}{Z}\right) .
$$

Finally, governments maximizing consumption will tax good $\mathrm{z}$ up to the point where 


$$
\left|\varepsilon_{z}^{c}\right|=1-\frac{Z^{\prime}}{Z}
$$

Given these values, it will be always true that

$$
\left|\varepsilon_{z}^{r}\right|=\left|\varepsilon_{z}^{p}\right|<\left|\varepsilon_{z}^{s}\right|=\left|\varepsilon_{z}^{w}\right|
$$

and

$$
\left|\varepsilon_{z}^{r}\right|=\left|\varepsilon_{z}^{p}\right|<\left|\varepsilon_{z}^{c}\right|
$$

Therefore $t_{z}^{r}$ and $t_{z}^{p}$ will be higher than $t_{z}^{s}, t_{z}^{w}$ and $t_{z}^{c}$, holding $p_{z}$ constant. When comparing the absolute values of $\varepsilon_{z}^{s}$ and $\varepsilon_{z}^{w}$, and $\varepsilon_{z}^{c}$, the two former will be bigger than the latter only if $\left|1-\int \frac{Z^{\prime}}{Z}\right|>\left|\frac{Z^{\prime}}{Z}\right| \cdot{ }^{10}$ This will be the case when the demand for good $\mathrm{z}$ is relatively elastic. This indicates that when the demand for good $\mathrm{z}$ is relatively elastic, it will be true that

$$
t_{z}^{c}>t_{z}^{s}=t_{z}^{w} .
$$

This result follows the same intuition as Ramsey (1927) that establishes that goods of more elastic demand should not be taxed as heavily as goods of more inelastic demand.

\section{$6 \quad$ Policy implications and conclusions}

This paper analyzes the competition between legal and pirate products. In this paper this competition is influenced by the government through taxes on legal products and spending toward the prosecution of illegal products. The former favors pirate products and the latter favors legal products. Despite the fact that governments tend to design policies that favor legal products, government spending needs to be financed through taxes and therefore the government faces a trade-off between both instruments. This trade-off may be softened if governments use tax revenues from other goods to finance their spending on prosecution as opposed to using tax revenues from the goods affected by piracy.

As shown in the results above, the optimal level of spending and taxes varies from policy to policy. Despite these discrepancies across policies, there exist some general results that are equal across policies. I find that taxes on legal products increase the higher $\Delta \theta$, the higher $c_{1}$ and the lower $c_{2}$. All three conditions state that in more advantageous situations for the legal producer, it is optimal for the government to set higher level of taxes on the good affected by piracy regardless of the goal it is pursuing.

I also find differences across policies. Those policies where the government maximizes consumer surplus or total welfare require high level of taxes on the good affected by piracy and high levels of spending in prosecution. Those policies targeting the minimization of piracy require the lowest levels of taxes and spending. Those policies maximizing consumption (legal and pirate) require intermediate level of taxes on the good affected by

\footnotetext{
${ }^{10}$ The expression $\frac{\int Z^{\prime}}{Z}$ takes value -1 when evaluated between the values $\infty$ and $p_{z}+t_{z}$.
} 
piracy and intermediate level of spending. Similarly, different governments use tax revenues from other goods in the economy to finance part of the spending in prosecution. Taxes on other goods will be highest under governments maximizing its size and minimizing piracy. Other types of governments will impose lower taxes on other goods and its magnitude will depend on the elasticity of demand of those goods.

Since the value that maximizes tax revenue from the pirated good is either $t_{2}^{r}$ or $t_{2}^{c}$, I can compare all the other values to these two and determine under which regimes the government is taxing too much or too little and therefore obtaining less tax revenue than it would with $t_{2}^{r}$ and $t_{2}^{c}$. This is the case for $t_{2}^{s}$ and $t_{2}^{w}$ since they are higher than $t_{2}^{r}$ and $t_{2}^{c}$ (the government is imposing higher taxes and collecting less money). Similarly, since $t_{2}^{p}$ is lower than $t_{2}^{r}$ and $t_{2}^{c}$, the government is imposing less taxes and collecting less money. Even though the latter assertion makes perfect sense, the former is in direct contradiction with the findings on the level of spending. These two contradictory results are only consistent with each other if the higher level of spending diminishes the demand for the pirate product to the point where the increase in demand for the legal product is bigger than the decrease in demand due to the increase in tax. See in Figure 2 that an increase in $G$ may bump up the Laffer curve and increase tax revenue per unit of tax. Unfortunately, this increase in $G$ must be financed with an increase in $t_{2}$ and the government faces a trade-off between tax revenue $(G)$ and efficient taxation $\left(t_{2}\right.$ higher than the maximum point in the Laffer curve). This occurs because an extra unit of spending $G$ increases the demand of legal products by less than one unit, and therefore the government must increase tax levels to finance such spending increase.

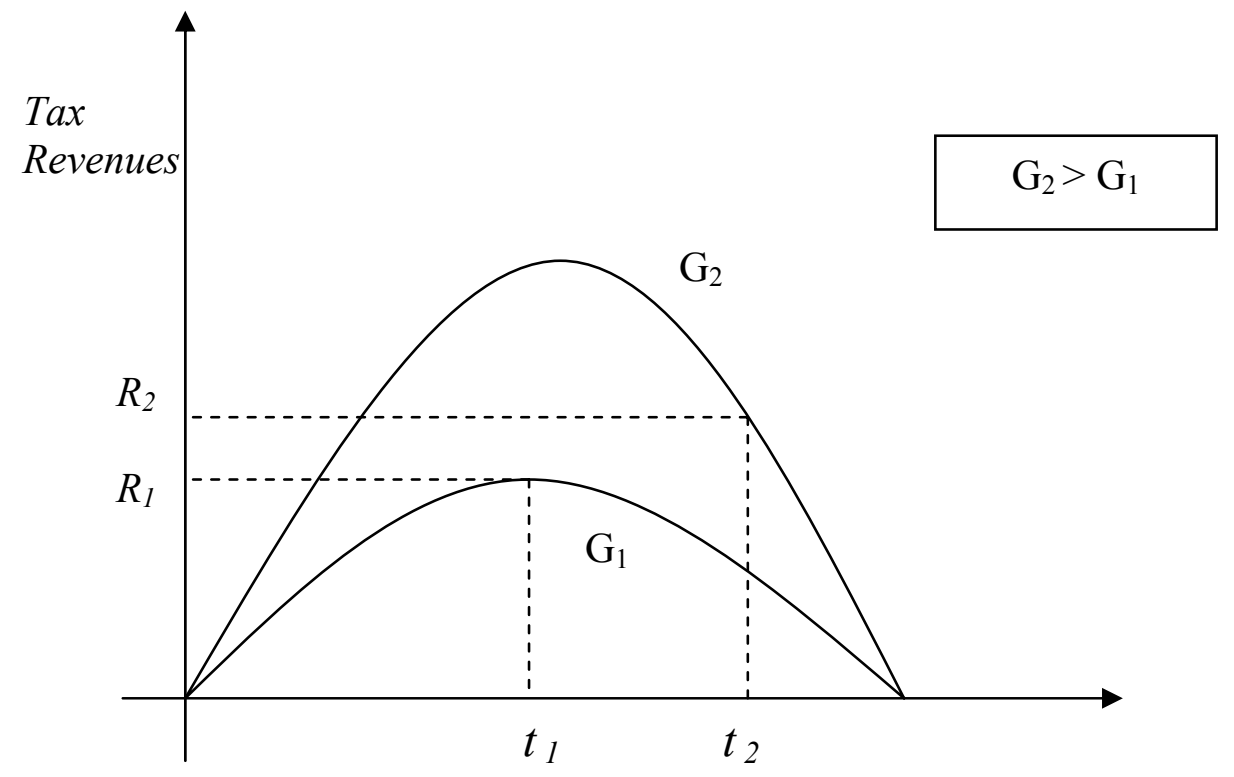

Figure 2

These results denote that different government goals require different level of taxes and spending. The results suggest that governments most worried with the eradication of piracy to foster innovation and foreign investment should lower taxes, acting through the 
demand side (consumption tax) and not through the supply side (spending on police). This goes against the traditional approach that restricts supply through the increase of regulation and spending on monitoring. Varian (2005) specifies very clearly that when the cost of sharing is very low (as it is in the internet or street sales) piracy will emerge naturally. In such a case, not even regulation or police will deter the emergence of demand for pirate products.

Interestingly the results obtained here imply that a government more interested in increasing future consumption will have the lowest level of taxes and spending. Doing this, governments eradicate piracy and foster innovation that will increase future consumption. This changes when the government worries about consumer surplus and society welfare. This is due to the fact that there is a shift of preferences from consumers with low consumption value to consumers with high consumption value and firms' profits. This is consistent with well-spread evidence that poor countries have less incisive policies of IPR protection, and therefore they could be acting optimally.

In conclusion, this paper analyzes the need for coordination between demand and supply policies when governments want to prevent the emergence of pirate markets and foster invention of new products in the future that will ultimately speed overall economic growth. Results in the paper suggest that policies valuing high-value consumers and firms' profits will tend to rely more on supply side policies (increase spending in monitoring policies), and policies targeting the elimination of piracy will tend to rely more on demand side policies (reducing taxes on pirated products). Policies that want to maximize society consumption (regardless of the value of consumption) will balance their use of taxes and spending and use intermediate levels of these. Finally, governments aiming to maximize their size (due to political aspirations of government officials) will tax at the maximum of the Laffer curve and maximize their spending.

Other future extensions of this research should involve the treatment of time and international borders. In this paper, I use a static model to study the interactions between legal and pirate products in a world with differentiated products. Including the dimension of time in a setting like this is the natural next step. Doing so would enable one to study how the incentives to innovation and production vary as the importance of piracy changes. Similarly, most of the inventions in the world occur in a few countries which license away these innovations to other countries that do not have the resources to produce the innovation themselves. Future research should also model the possibility of observing innovation abroad and within the same country and study how piracy abroad and within the same country affects innovation incentives.

\section{$7 \quad$ References}

Banerjee, D. (2003) "Software Piracy: A Strategic Analysis and Policy Instruments," International Journal of industrial Organization, 21: 97-127.

Besen, S. and L. Raskind (1991) "An Introduction to the Law and Economics of Intellectual Property," Journal of Economic Perspectives, 5: 3-27.

Blackburn, D. (2002) "Complementarities and Network Externalities in Casually Copied Goods," Estudios de Economía, 29: 71-88. 
Blackburn, D. (2005) "On-line Piracy and Recorded Music Sales," mimeo, Harvard University.

Chen, Y, and I. Png (2003) "Information Goods Pricing and Copyright Enforcement: Welfare Analysis," Information Systems Research, 14: 107-123.

Chen, Y. and I. Png (2004) "Parallel Imports and Music CD Prices," Working Paper, National University of Singapore.

Dam, K. (1999) "Self-Help in the Digital Jungle,” Journal of Legal Studies, 28: 393-412.

EL PAIS, 4-14-2004, "La SGAE cifra en 17 millones los discos vendidos en los 'top manta' el año pasado" newspaper article published in EL PAIS in 4-14-2004.

Fine, M. (2000) “Soundscan Study On Napster Use And Loss of Sales,” www.riaa.com

Gayer, A. and O. Shy (2003) "Copyright Protection and Hardware Taxation," Information Economics and Policy, 15: 467-483.

Grgeta, E. (2004) "Copies and Originals in a Horizontally and Vertically Differentiated Market with Habit and Quality Differences," mimeo, University of Chicago.

Hann, I., K. Hui, T. Lee and I. Png (2002) "The Value of Online Information Privacy: Evidence from the USA and Singapore," Working Paper, National University of Singapore.

Hui, K. L. and I. Png (2003) "Piracy and the Legitimate Demand for Recorded Music," Contributions to Economic Analysis \& Policy, 2: No. 1, Article 11.

IFPI (2001) “Music Piracy 2001,” IFPI's annual global piracy report.

IFPI (2002) “Music Piracy 2002,” IFPI's annual global piracy report.

Klein, B., A. Lerner and K. Murphy (2002) "The Economics of Copyright "Fair Use" in a Networked World," American Economic Review: Papers and Proceedings, 92: 202-205.

Landes, W. and D. Lichtman (2003) "Indirect Liability for Copyright Infringement: Napster And Beyond," Journal of Economic Perspectives, 17: 113-124.

Lessig, L. (2004) Free Culture. The Penguin Press: Toronto, ON, Canada.

Liebowitz, S. (2003a) "Will MP3 downloads Annihilate the Record Industry? The Evidence so Far," in G. Libecap (ed.) Advances in the Study of Entrepreneurship, Innovation, and Economic Growth, JAI Press: Amsterdam.

Liebowitz, S. (2003b) "Pitfalls in Measuring the Impacts of File Sharing," Working Paper, UT Dallas, School of Management.

Liebowitz, S. (2004) "Peer-To-Peer Networks: Creative Destruction or Just Plain Destruction?" Working Paper, UT Dallas, School of Management. 
Oberholzer, F. and K. Strumpf (2004) "The Effect of File Sharing on Record Sales: An Empirical Analysis," mimeo, Harvard Business School.

Ramsey, F. (1927) "A Contribution to the Theory of Taxation," The Economic Journal, 37: 47-61.

Rob, R. and J. Waldfogel (2004) "Piracy on the High C's: Music Downloading, Sales Displacement, and Social Welfare in a Sample of College Students," NBER Working Paper No. 10874.

Romer, P. (2002) "When Should We Use Intellectual Property Rights?" American Economic Review: Papers and Proceedings, 92: 213-226.

Shaked, A. and J. Sutton (1982) "Relaxing Price Competition through Product Differentiation," The Review of Economic Studies, 49: 3-13.

Slive, J. and D. Bernhart (1998) "Pirated for Profit," The Canadian Journal of Economics, 31: 886-899.

Takeyama, Lisa N. (1994) "The Welfare Implications of Unauthorized Reproduction of Intellectual Property in the Presence of Demand Network Externalities," Journal of Industrial Economics, 42: 155-166.

Takeyama, Lisa N. (1997) "The Intertemporal Consequences of Unauthorized Reproduction of Intellectual Property," Journal of Law and Economics, 40: 511-522.

Tirole, J. (1991) The Theory of Industrial Organization. MIT Press: Cambridge, MA.

Varian, H. (2005) "Copying and Copyright," Journal of Economic Perspectives, 19: 121138.

Wauthy, X. (1996) "Quality Choice in Models of Vertical Differentiation," International Journal of Industrial Organization, 44: 345-53.

Zentner, A. (2006) "Measuring the Effect of Online Music Piracy on Music Sales," Journal of Law and Economics, 49: 63-90. 